\title{
Photographing \\ the Downy Woodpecker
}

by H. S. Dommasch,

Medical Photography Department, University of Saskatchewan, Saskatoon

Most of you will agree that bird watching is very interesting and rewarding. If you are able to bring back a photographic record of what you have seen your thrills will be even greater and you will discover that "Hunting with a Camera" is fine sport.

I want to tell you-and show you -how much pleasure a woodpecker family has given to us. Early in May, 1962, my wife and I and some friends were down at Beaver Creek when a drumming sound invited us to give a closer look to the wooded area. There the woodpecker was-sitting on a dead limb, hammering with his bill so fast that our eyes could not ollow the movement of his head. The ird was slightly larger than a sparlow and the sharply barred black and white pattern of its plumage identiied it as a Downy Woodpecker, the est known of the American species. We took another look at the suroundings and found some wood havings under a dead tree which ould mean that the bird was ready $b$ build its nest here. From then on e kept the nest under steady sureillance. Over a period of days the ole got bigger and bigger until it as so large that we could not see he bird when it hopped in. Day after ay we went back, knocked at the ee and one of the adult birds would ist peek out of the nest entrance to ok at the intruder One day our hocking was answered by sounds ke hissing and rasping cries. This und was produced by the nestlings; nally the family had arrived.

A friend suggested that perhaps a ple could be cut in the back of the ee and a glass plate put in, through hich we could take photographs. As e did not want to harm the woodcker, we consulted Dr. S. Houston who encouraged us to go ahead with the plans. We opened the back of the tree very carefully and found that the nestlings were $81 / 2$ inches below the entrance. The noisy youngsters were naked and hcmely looking. (I believe when we were born we did not look any better-except to our parents.) We observed that the male, who has a bright red spoit on the back of his head was more active in feeding the youngsters than the female. After 6-8 days we noticed that the mother bird did not come back to the nest and we were worried about her until we read that the female sometimes loses interes't in her offspring long before they leave the nest. Dad had taken charge of the family. "Well," I said to my wife, "if that isn't just like a woman!"

When the young were only a few days old the food was mashed to fine pieces, but the chunks of food got bigger and bigger as the nestlings grew. You would hardly expect a woodpecker to capture flying insects in mid air, but they have been observed doing this. We actually saw the adult bird feeding moths and butterflies to the young.

It was a fascinating experience to watch the family of woodpeckers through the "window", but I would like to make a few points clear. The lucite plate which we used instead of glass was just put in for 30-45 minutes while we took our pictures. We always made sure that the sun at no time was shining into the nest, so the nestlings were protected from its scorching rays. Wildlife photography is a lot of fun-but you as the photographer are responsible for the animals' welfare during and after the shooting session. Remember that no bird picture is worth the taking if it means death to the nestlings. 


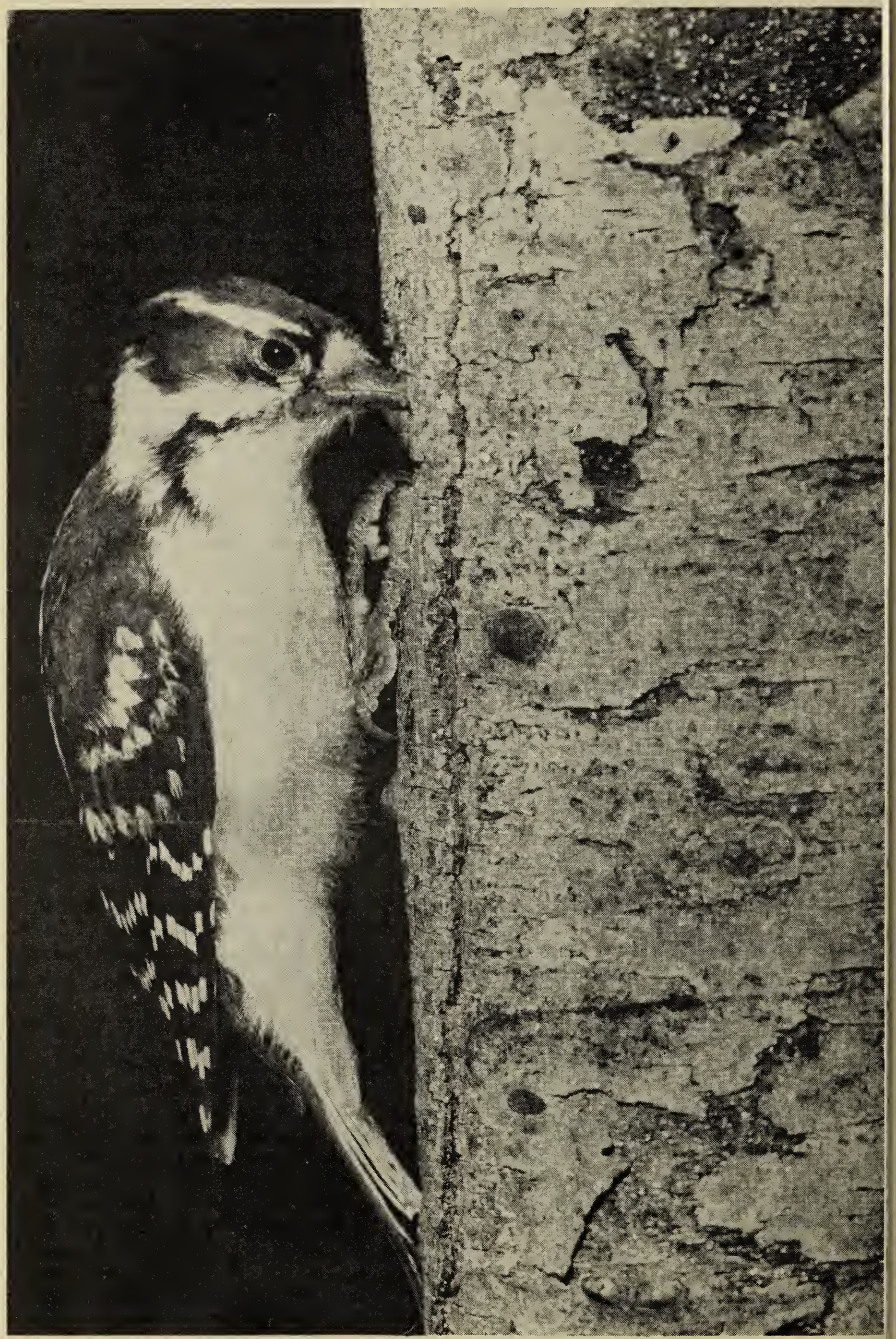

Photo by H. S. Dommasch.

The Downy Woadpecker is slightly larger than a sparrow. The tail feathers are very stiff and pointed and serve as a prop when the bird is clinging to a tree trunk. 
DOWNY WOODPECKER

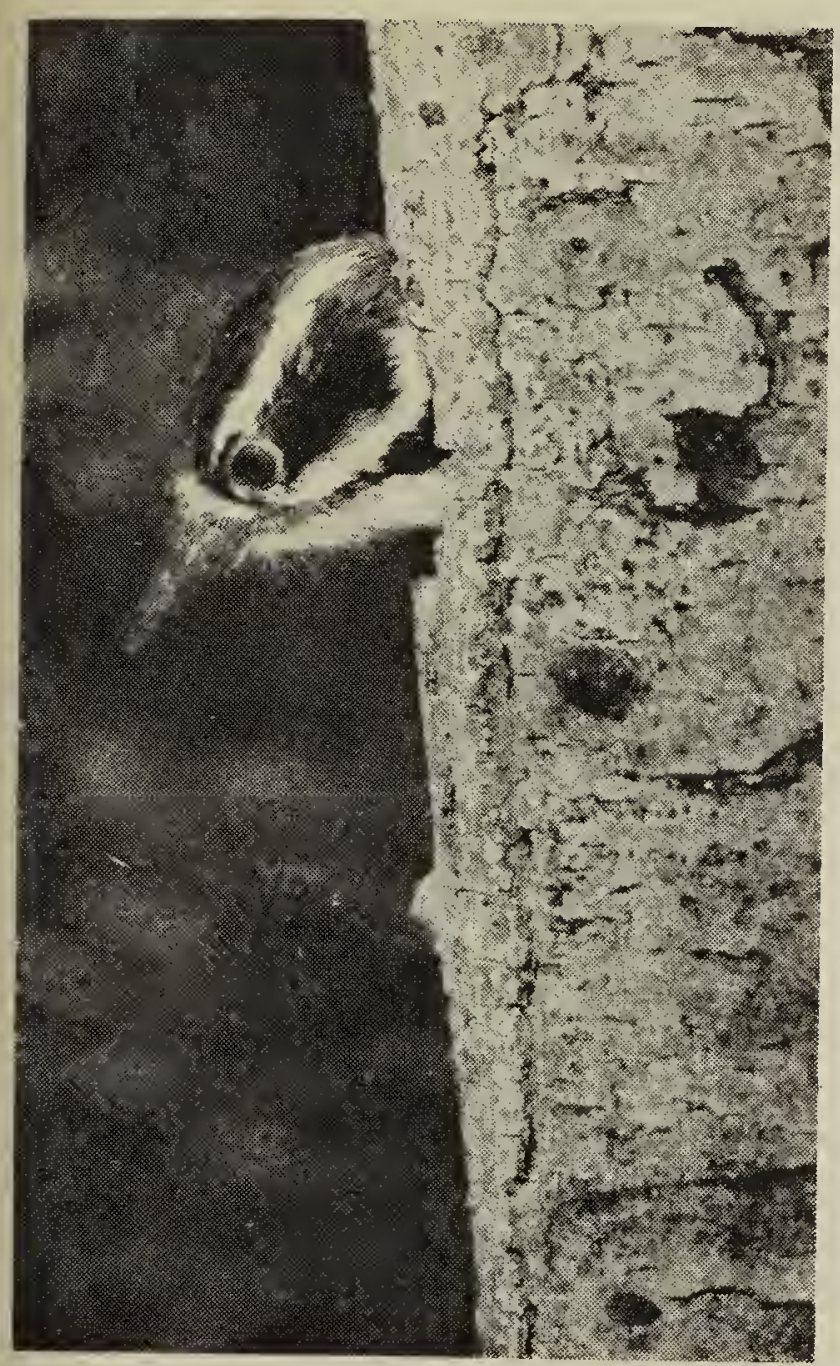

The female is looking out to see who is knocking at the tree.

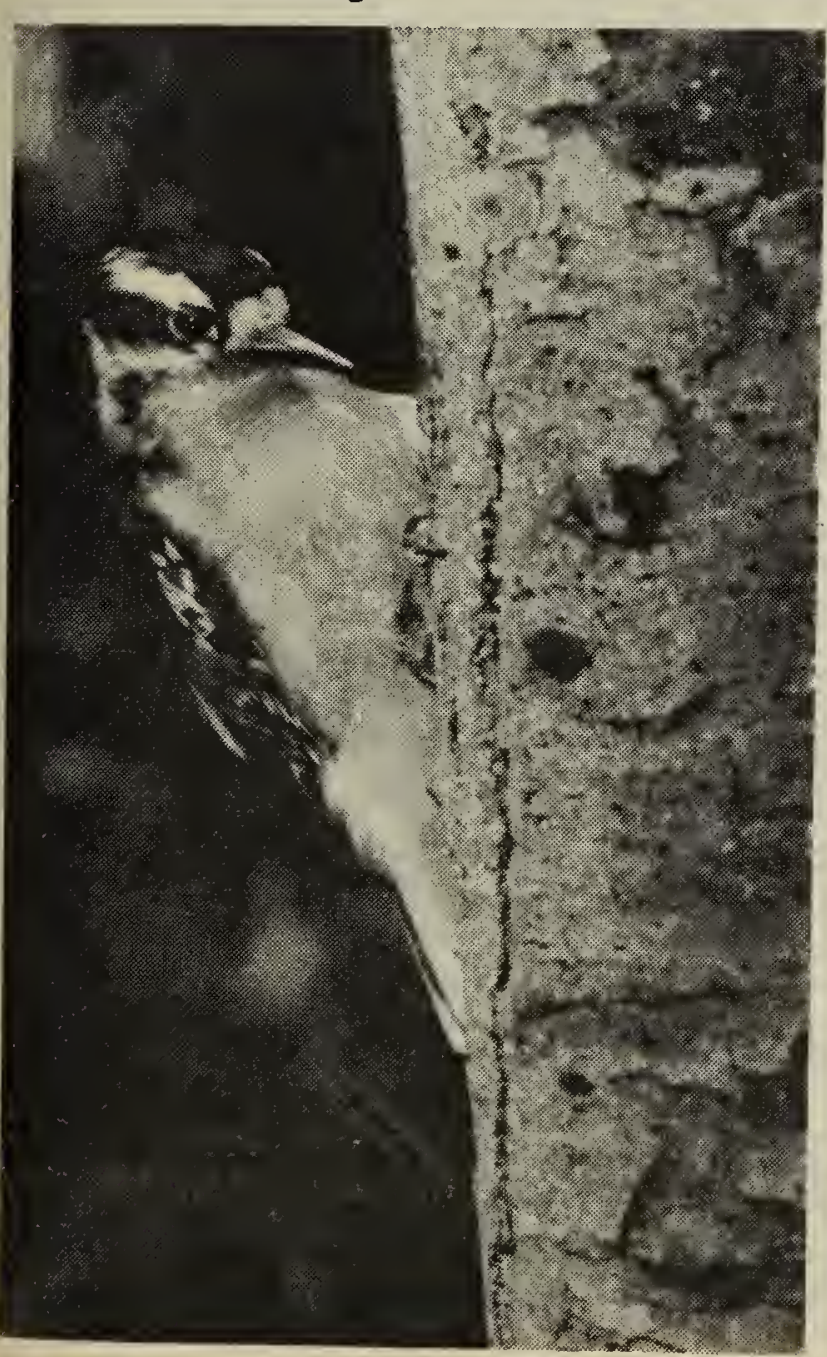

"Hey! What are you doing there?"

\section{Photographs by H. S. Dommasch}

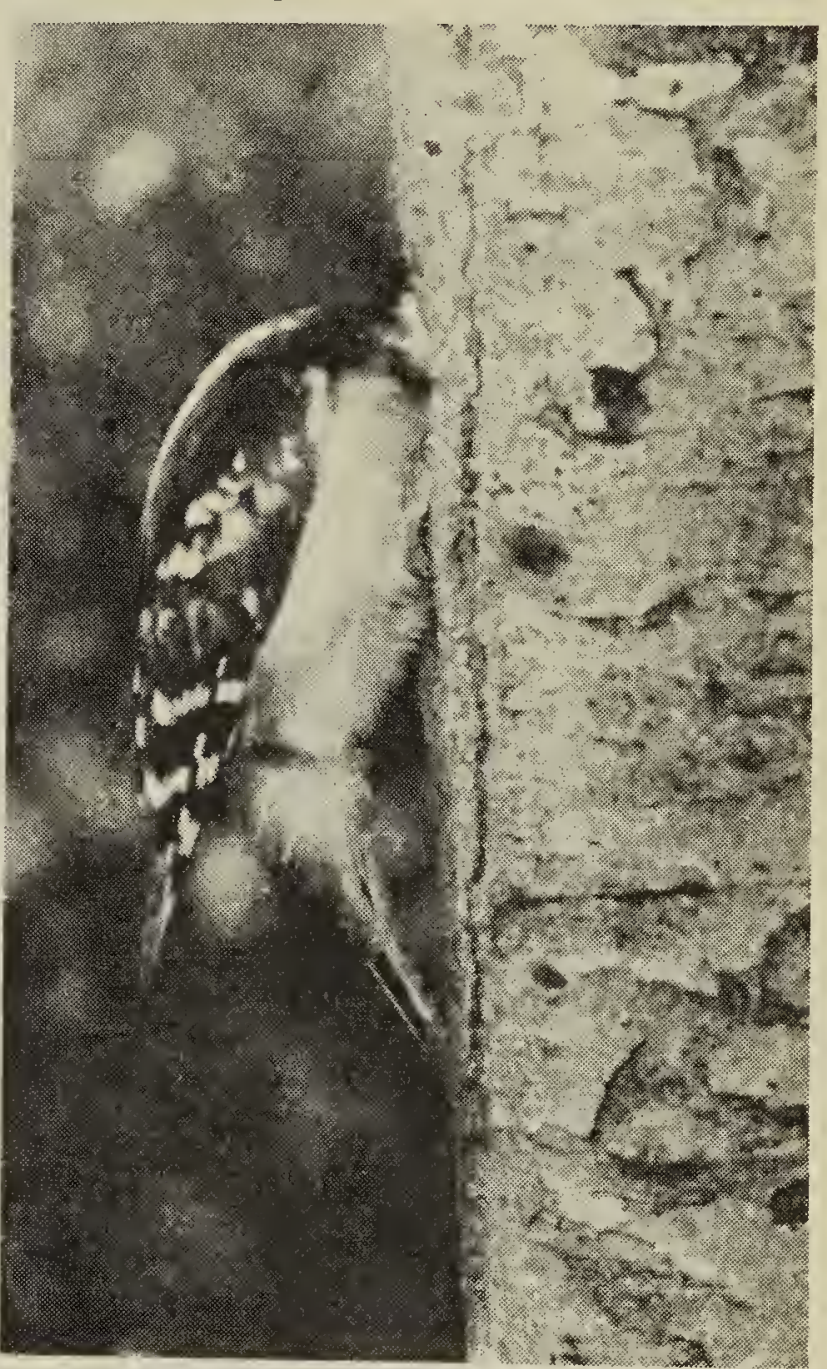

"Hello children I am coming down."

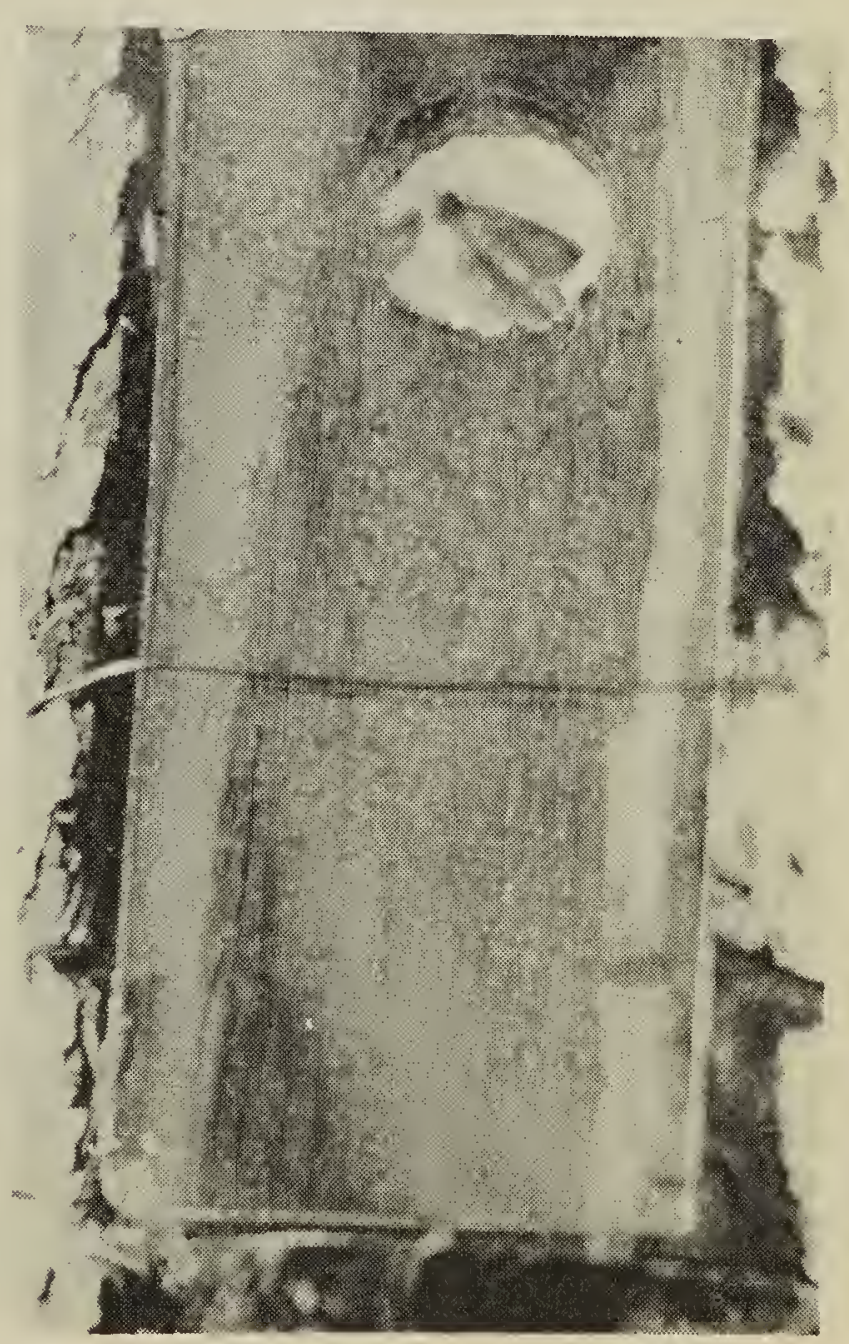

Inside the nest. A butterfly is about to be brought in. 
Vol. XXII, No.

(1) (x)

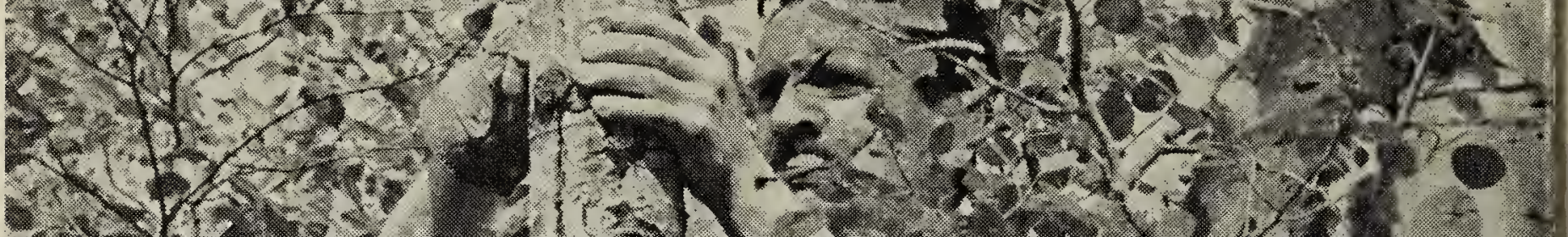
4. at: $\div y^{\prime}$

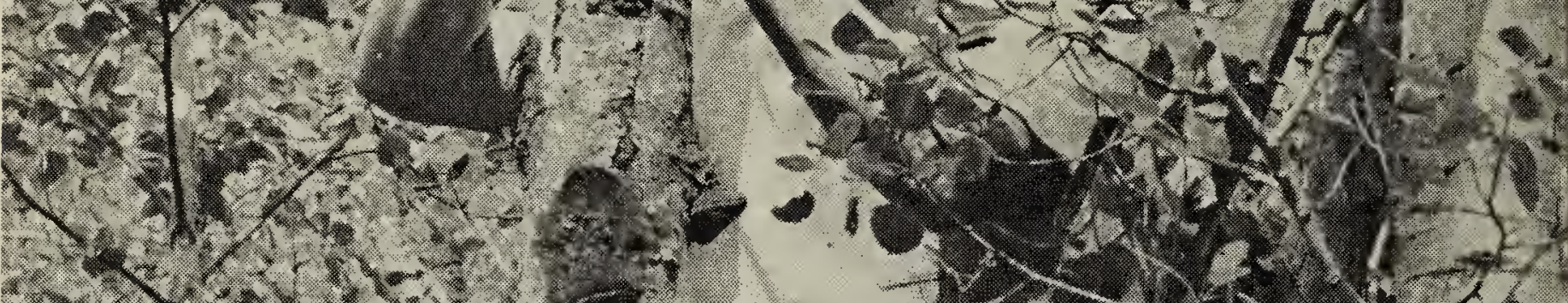
1.t.

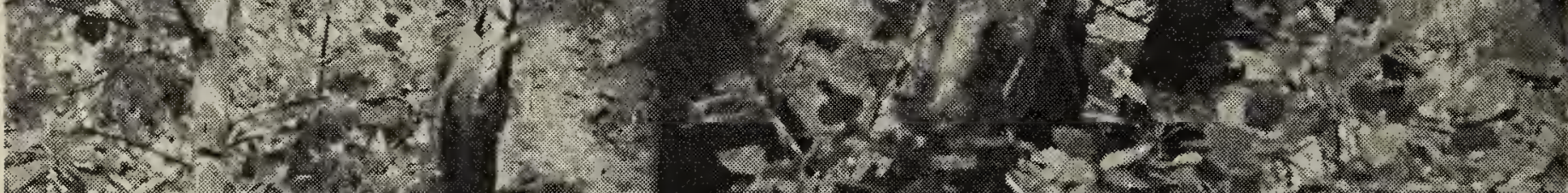
$x+3 x^{2}$ a. $-1,5$

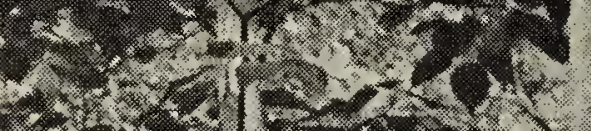
a.t. $x=1$, t $x+1$. 2. 801

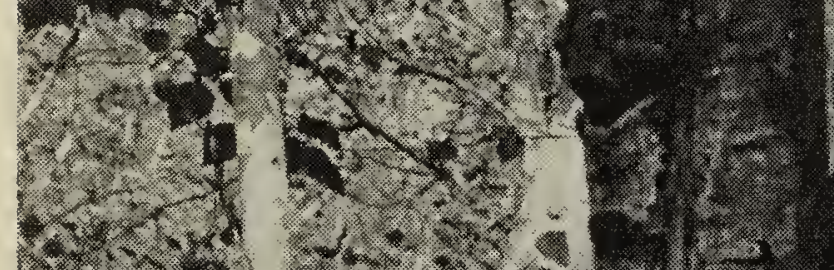

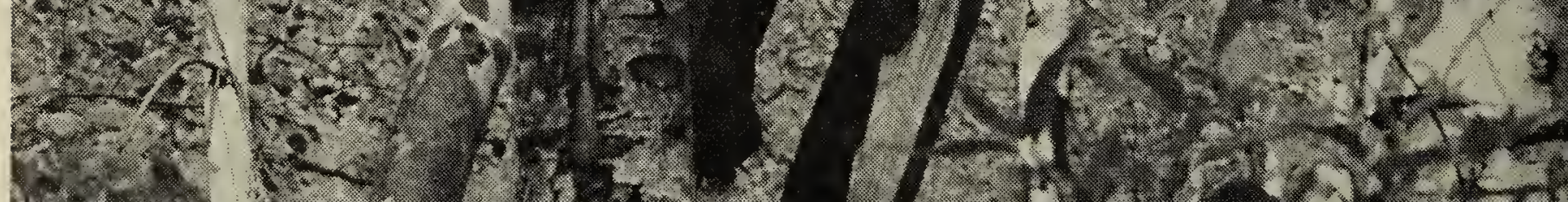

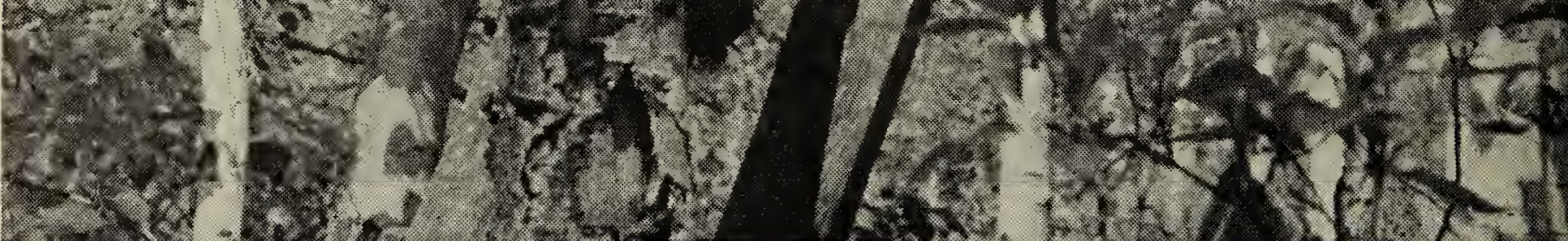

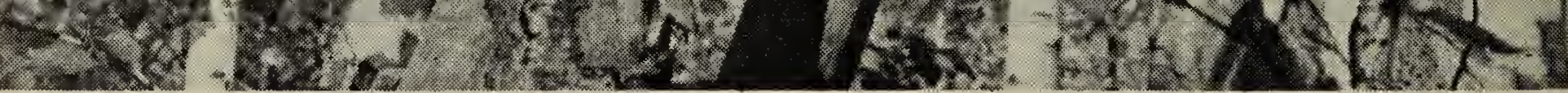

Putting a lucite plate in the back wall of the nest, 15 feet up in a dead aspen, so that the young Downy Woodpeckers could be photographed. 


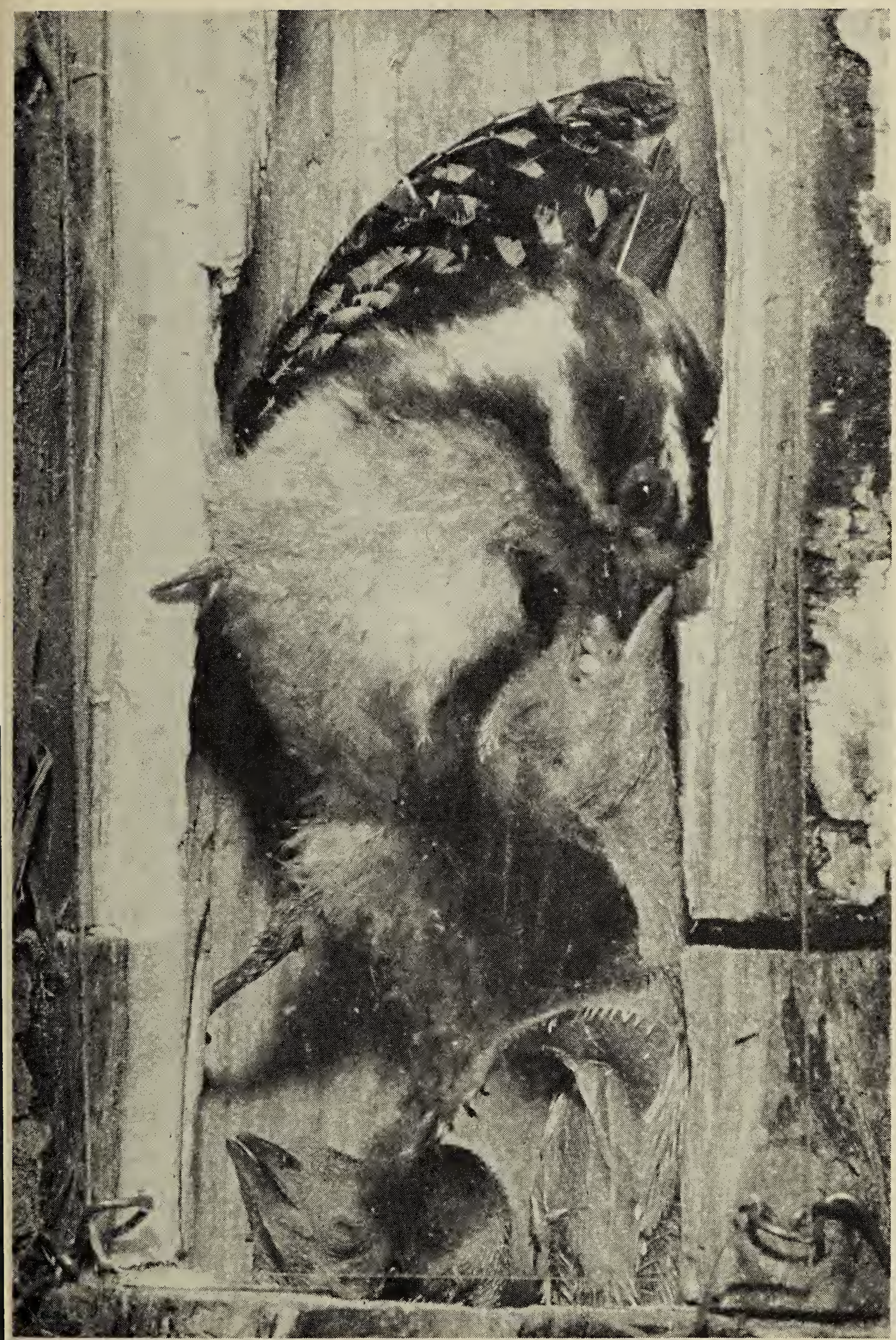

Photo by H. S. Dommasch.

The Downy Woodpecker feeding a young bird in its nest in a dead aspen. Three young birds can be seen in the photo. 